\title{
CORRESPONDENCE
}

\section{UK scientific societies need support to increase their impact}

British scientists can connect to new Members of Parliament (MPs) through UK professional bodies other than the Campaign for Science and Engineering and the Royal Society (Nature 465, 135; 2010). These bodies include the Institute of Physics, the Royal Society of Chemistry (RSC) and the Society of Biology. Scientists need to subscribe to and lobby these as well as the learned society for their own specialism.

The RSC, for example, has led the way on parliamentary liaison with an MP-pairing scheme that precedes that of the Royal Society by many years. The RSC parliamentary unit provides places at the negotiating table for physicists, biologists, engineers and some parliamentarians. It also runs an annual Parliamentary Links Day, which has resulted in several successful interdisciplinary policy ventures.

More support from UK scientists will provide these organizations with resources, guide them in what to do and lend them the democratic credence that parliamentarians value. This is a critical time to maintain the British government's investment in science in real terms.

Jonathan Cowie Concatenation Science Communication, Thurnby Lodge, Leicester LE5 2WG, UK www.science-com.concatenation.org

\section{On the occurrence of similar traits in related organisms}

In Eugenie Scott's review of my book How Science Works: Evolution (Nature 465, 164; 2010), she perpetuates the common error of confusing the definition of the biological term 'homology' with its interpretation.
The word was invented in 1843 by anatomist Richard Owen to mean "the same organ in different animals under every variety of form and function". But Owen did not believe in evolution and interpreted the observation of homologies as the preferences of a supernatural agent.

Modern biologists define homology differently, to mean the occurrence of similar traits in different organisms that are evolutionarily related by descent. To cite the modern definition as part of the evidence for evolution is a classic example of a circular argument, as pointed out by evolutionary biologist Mark Ridley in his textbook Evolution (Blackwell, 2003).

The solution is to avoid using 'homology' when discussing the evidence for evolution, and instead use 'similarity', the meaning of which is intuitively obvious but implies no particular interpretation. Homology can then be used to describe one result of evolution.

As I indicate in my book, the strongest evidence for evolution is the widespread observation of similarities at all levels of biological observation - from the anatomical to the molecular.

R. John Ellis Department of Biological Sciences, University of Warwick, Coventry CV4 7AL, UK e-mail: r.j.ellis@warwick.ac.uk

\section{Adaptive strategy recommended for US ocean planning}

The United States could learn from the experience of other nations in implementing its proposed ocean-management policy for coastal and marine spatial planning (Nature 465, 9; 2010).

For example, New Zealand has had problems in setting up aquaculture-management zones. These difficulties stem from an inflexible spatialplanning policy known as zoning, traditionally used for land-use management.

Long-term zoning depends on the allocation and maintenance of spatially explicit property rights. But many nations do not have these rights or they may differ markedly among sectors in the marine zone (see, for example, M. T. Gibbs Mar. Policy 31, 112-116; 2007).

Decisions on marine spatial zoning are too frequently based on disparate and limited data sets that have coarse spatial and temporal resolution. They may also represent an outdated picture of marine community composition and habitat altering as a result of climate change.

The United States would be well advised to use a more adaptive approach to property rights and spatial management in its coastal and marine spatial planning.

Mark T. Gibbs, Rodrigo Bustamante, Anthony J. Richardson CSIRO, Division of Marine and Atmospheric Research, Cleveland, Queensland 4163, Australia e-mail:mark.gibbs@csiro.au

\section{Reward research that benefits society, with kudos or even cash}

Broadening the impact of university research on society (Nature 465, 416-418; 2010) should be included in the academic reward structure.

The present scientific reward system threatens to imprison academics in their ivory towers. It is ruled by bibliometric quality indicators spawned by the rise in systematic performance evaluations (L. K. Hessels, $H$. van Lente and R. Smits Sci. Public Policy 36, 387-401; 2009). Originally a means of communication, publication has become an end in itself.

Demonstrating the relevance to society of a research proposal helps to get it funded. But in practice, scientists are rewarded for their contribution to a field's progress, and not for its impact on society or the economy.

Hiring and promotion criteria and the evaluation of research groups and institutes need to be expanded to include factors for broader impact, alongside publication records and citation scores. Research councils could consider shifting part of their money from input funding to output funding. Cash awards might also be offered for broader-impact results (Nature 465, 398; 2010).

Laurens K. Hessels, Harro van Lente Innovation Studies Group, Utrecht University, PO Box 80115, 3508 TC Utrecht, the Netherlands e-mail: I.hessels@geo.uu.nl

\section{Nature Europe site should highlight most productive countries}

Your newly launched website showcasing Nature Publishing Group's European output (www. nature.com/regions/europe) has sections for France, Germany and Italy. We hope that other regions in Europe will soon be given more prominence.

Taking all biomedical papers listed in PubMed in March 2010 by country, a simple estimation (see go.nature.com/QTb96x) shows that France, Germany and Italy fall some way down a list of European countries in which people are most productive in bioscience (publications per capita) or where income is most effectively converted into bioscience papers (publications per US\$ million gross domestic product). By these criteria, they are in fact overtaken by the Scandinavian countries, Switzerland, the Netherlands and the United Kingdom.

Chris T. Evelo, Andra Waagmeester Department of Bioinformatics, Maastricht University, 6200 MD Maastricht, the Netherlands e-mail:chris.evelo@bigcat.unimaas.nl

Contributions may be submitted to correspondence@nature.com; see go.nature.com/cMCHno. 